\title{
THE TREATMENT IS WITHIN THE DISEASE: TOURISM PARADOX, TOURISM EQUINOX AND TOURISM DETOX
}

\author{
Irfan Arikan ${ }^{1}$ \\ Ilker Ünsever ${ }^{2}$
}

\begin{abstract}
Having the tourism industry as the only development model for a country with its natural and cultural resources could not only destroy the social life but also the tourism industry itself. Although the equation "more tourists=more tourism income" is so simple, it is not a sustainable approach for the development plans of the destinations. This process leads to overuse of natural and cultural attractions and places pressures on tourism earnings. "Tourism paradox" is the name of this concept. Tourism paradox is the name given to this phenomenon where tourism industry destroys natural and cultural environment that is necessary for tourism activities. The growth of tourism cannot be always considered as having a positive impact for destinations. The balance, which does not change and disturbs the social and economic relations at the destination is called "tourism equinox". New projects and approaches to solve the problems caused by the growth of urban populations and establish healthy sustainable tourism destinations are becoming more important than ever. Tourism detox is a treatment that is intended to remove harmful substances from the destination. Detox is a radical decision and it is not an easy process. Therefore, spatial reorganization and urban regeneration play a crucial role for the marketing of destinations and this transformation action affects all infrastructure facilities, restorations of old buildings, reorganization of historical zones, and revitalizing the architectural style of the destinations. This paper investigates the influence of tourism paradox and equinox on destinations in relation to tourism activities and the protection of natural and cultural resources with the help of tourism detox. It primarily relies on qualitative research to understand the main futures of tourism paradox, equinox and detox taking the negative impacts of tourism into consideration. As research methodology a literature review and the sources of secondary data were used.
\end{abstract}

Keywords: Tourism Paradox, Tourism Equinox, Tourism Detox, Tourism Development, Sustainability.

\section{TOURISM PARADOX}

When looking at the increase of tourism in a destination, it can be said that tourism is a valuable part of the economy.The proposal offered by today's competitive paradigm that higher the number of tourists visiting a destination, the higher will be the income for the destination sounds good at first. Parallel with the increased tourism activities, new buildings, new lifestyles, foreign capital and new socio-economic relationshipsappear rapidly at the destination and replace the traditional ones. The increased number of tourist arrivals gives the appearance of increasing desirability of the destination. However, there will be huge amount of social, cultural, economic and environmental problems faced by the local people as well as tourists at the destination; socially, by disturbing the sociocultural balance of local communities,culturally commoditization of local cultures and overcrowding ofheritage sites, environmentally increasing carbon footprint, pollution of water resources and destruction of ecosystems, economically prices inflation and land speculation (www.exofoundation.org/the-paradox- of-tourism).

\footnotetext{
${ }^{1}$ Professor Dr., IMC FH Krems, University of Applied Sciences, Krems, Austria.

${ }^{2}$ Lecturer, Department of Tourism Administration, Boğaziçi University, Istanbul, Turkey.
} 
Having the tourism industry as the only development model for a country with its natural and cultural resources could not only destroy the environment and social life but also the tourism industry itself. Although the equation "more tourists = more tourism income" is so simple, it is not a sustainable approach for the development plans of the destinations.It is obvious that tourism generates beneficial outcomes as much as it produces negative impacts in the conservation of traditional settlements and historical destinations with their natural and cultural resources. Therefore the relationship between culture and tourism has been defined with terms such as: "paradox, contradiction and conflict, dynamic and complex" (K1liç\&Aydogan, 2015). The growth of tourism cannot be always considered as having a positive impact for destinations. Because of the increase of the tourism industry, many historic destinations started to lose their historical identity and suffer from overcrowding (Diekmann\&Gillot, 2010).

"The tourism paradox" begins to appear at this stage since the natural and cultural resources that are worth seeing are consumed by the travelers. Tourism paradox is the name given to this phenomenon where tourism industry destroys natural and cultural environment that is necessary for tourism activities. Tourism paradox is also the name of unsustainable tourism. Projects that focus on and emphasize the economic and social benefits should be undertaken in order to protect these values in the end. Besides the economic aspect of conserving cultural and natural heritage it is also very important to protect the destination from the negative effects of tourism.Heritage is not only something that people wish to pass on generation by generation, it is also something that has become increasingly scientific so that preservation and survival is something that is created through a number of principles, processes and practices (Timothy\&Boyd, 2003).

Tourism is like fire,it can cook the meal or, burn the house. This famous Asian saying underlines the fact tourism is indeed a double edged sword, and that tourism impacts highly depends how it is being developed, managed and consumed. Attractive landscape sites, such as sandy beaches, lakes, riversides, and mountain tops and slopes, are often transitional zones, characterized by species-rich ecosystems. The threats to and pressures on these ecosystems are often severe because such places are very attractive to both tourists and developers. The ecosystems most threatened with degradation are ecologically fragile areas such as alpine regions, rain forests, wetlands, mangroves, coral reefs and sea grass beds. Increased construction of tourism and recreational facilities has increased the pressure on natural resources and on scenic landscapes. Direct impact on natural resources, both renewable and nonrenewable, in the provision of tourist facilities can be caused by the use of land for accommodation and other infrastructure provision, and the use of building materials. Forests often suffer negative impacts of tourism in the form of deforestation caused by fuel wood collection and land clearing. Often tourism fails to integrate its structures with the natural features and indigenous architecture of the destination. Large, dominating resorts of disparate design can look out of place in any natural environment and may clash with the indigenous structural design. Lack of land-use planning and building regulations in many destinations has facilitated sprawling developments along coastlines, valleys and scenic routes (http://www.gdrc.org/uem/eco-tour/envi/one.html). 


\section{TOURISM EQUINOX}

Destinations have suffered from uncontrolled tourist development and tourism paradox during the last decades, having as consequence the destruction of natural eco-systems, air and water pollution, the shortage of water, problems of waste disposal, or the transformation of small villages into centers of urbanization. Fortunately tourist's mentalities are changing and the slogan of "non-destructive or sustainable tourism" is becoming important for travelers and for authorities. New positive kinds of holidays are being developed; they deal with the problems of mass tourism, caring for cultural, social, and natural features of the destination (http://www.karl.aegee.org/oem/articles/oe8/tfreedo.htm).

Presenting a balance between the sustainability of cultural and natural heritage and marketing for tourism purposes forms an important aspect of planning and managing cultural and natural heritage sites (Teo\&Huang, 1995).Can we protect the destinations from tourism paradox? New projects and approaches to solve this problem and to establish healthy sustainable tourism destinations are becoming more important than ever.The balance, which does not change and disturbs the social and economic relations at the destination is called "tourism equinox". The name "equinox" is derived from the Latin aequus (equal) and nox (night), because around the equinox, night and dayare about equal length.

Tourism has become a significant future of the economy and structure of the destinations around the world and also has played a major role in the transformation and redevelopment of industrial districts within destinations that have traditionally accommodated commercial activities.

Sustainable tourism has been promoted as a way of moderating the disadvantages of tourism, at the same time as make best use of the benefits in a way that is suitable for the greatest number of people (http://www.karl.aegee.org/oem/articles/oe8/tfreedo.htm). Tourism equinox encourages the development of cultural and rural tourism to sustain local cultures, traditional lifestyles and industries, it seeks to utilize resources and the environment in a sustainable way, and it aims to generate the local economy by providing opportunities for employment and economic development. Also it demands an awareness of the needs of local people, respect and appreciation for culture and the environment and achieves a balance between development and conservation.

One of the best examples of tourism equinox for worldwide is Yamaguchi, located on the periphery of Honshu, the main island of Japan. After the rural areas of Yamaguchi lost $32 \%$ of its population, the local people of this destination understand that tourism equinox can be used to bring together a range of activities, products and experiences to useful economic advantage. The Yamaguchi tourism policy aims to satisfy both residents in rural areas, as well as visitors from urban areas (Murayama\&Parker, 2012).

According to Hermann Hinterstoisser, Head of the Nature Protection Department, Salzburgerlandthe great variety of beautiful landscapes in Austria offers many different aspects of multifunctionality. The protection and sustainable development of landscapes has to be a joint task for spatial planning, agriculture, forestry, nature conservation and tourism as a whole in order to maintain the diversity of the landscapes.Local communities need to control andself-regulate their tourist industries, and tourism offers the best options in terms of environmental protection and long-term, sustainable economic growth in these communities (Wearing,Wearing\&McDonald, 2012). It is expected that domestic and foreign visitors will in the future prefer greener, more serene, and more natural destinations 
where they can easily find the values stated in the basic principles of sustainable tourism, where they feel healthy, relaxed and securewith tourism equinox.

On the other hand, the growth of rural tourism have to be totally diverging with that of seaside tourism development that, without control could create huge holiday resorts and artificial villages with no identity. Many coastal regions in Portugal, Italy, Greece and particularly in Spain, have suffered this problem, and coast line has been completely destroyed by blocks of apartments and huge hotels, without green or natural areas(Randelli,Romei,Tortora\&Tinacci, 2012).For a tourist destination the promotion and the image are fundamental and must be carefully constructed in order to get benefits. Tourism is a form of conspicuous consumption and tourists exhibit their identity and social standing by the destination they choose to visit and the image it presents. The social and economic impact of tourism, and consequently its effect on culture, is enormous in areas of mass tourism (http://www.karl.aegee.org/oem/articles/oe8/t-freedo.htm/). For that reason, tourism equinox try to solve this problem by advocating that the image presented should meet the needs of the local community and express their cultural heritage.

In Mallorca however, in the tourism sector the damage is caused by sheer numbers and by the fact that tourists are notoriously unconscious of their environmental behavior when away from home. Tourism is a consumer industry and it is difficult to impose better environmental standards on a transient population. For a long time Mallorcans have bemoaned the degenerative impact tourism has had on society, language and environment but have been happy to accept the considerable economic benefits. Many commentators advocate an expansion of 'new' tourists at the expense of 'old mass' tourists through a policy of diversification. Highly laudable providing total income from tourism remains constant or rises (Buswell, 2011). The objective is not denying tourists' access to the beaches and enjoy sun and party, but it should be controlled. The quality of the product has to be improved, because more and more tourists are becoming demanding and look for quality and for new experiences, new activities, new ways of enjoying their holidays (Segui, 1995).

Quality tourism is a form of soft tourism. The term soft tourism represents environmental and social compatibility as its priorities. In terms of environmental protection this means the creation of a balance between tourism and natural structures and resources, in other words tourism equinox. Consequently soft tourism is only practicable with a limited number of visitors. The most important measures to ensure a balance between tourism and environment could be a strict regulation of the flow of visitors, a proper signposting of hiking trails and cycle paths, the integration of the native population and an increased offer of guided tours. Soft tourism, agro-tourism and rural tourism arepossible solutions for sustainable form of quality tourism (K1lıç\&Aydogan, 2015), and also for tourism equinox at the destinations.

\section{TOURISM DETOX}

We have previously analyzed the issue of tourism paradox that was mainly about the negative progress of the tourism industry. The aforementioned tourism paradox affects the tourism destinations, where relations of tourism industry have dominated roles over its unplanned and uncontrolled economic and social structure with unbalanced funds. In tourism urbanization, cities or urban areas are commoditized for the consumers of the tourism industry; and tourists go to tourism cities to consume not only the facilities of the city but also to consume the whole city(Kaya, 2014). 
The concept of distortion through tourism followed by spoilage of tourism could be better observed in touristic resorts such as Kuşadası, Alanya and Fethiye in Turkey. It is clearly noticed that the nature, environment, social structure in the province and dominant cultural elements are speedily decreased. Consequently, some destinations that have become favorite resorts with their unique touristic attractions have lost their characteristics, some of them have become extinct and most of them have lost the identity. The people involved in tourism in these regions where the economy of the society is based on tourism, were in search for "more tourists" in order to satisfy their economic profit in a very addictive manner like drug addicts.

Is antisepsis possible? Dialectics are the reality: the treatment is within the disease! Just as in the case of drug addiction, it is possible to be cured from the addiction. Tourism paradox is toxidation of destinations with the negative effects of the tourism industry. The period of tourism paradox can be seen as an opportunity to protect the natural and cultural resources of the destination which is called tourism detox. Detox is a radical decision and it is not an easy process. Tourism detox is not the same as detox tourism, digital detox or unplugging from technology during holidays. Tourism detox is a treatment that is intended to remove harmful elements of tourism development from the destination. Therefore, spatial reorganization and urban regeneration play a crucial role for the marketing of destinations and this transformation action affects all infrastructure facilities, restorations of old buildings, reorganization of historical zones, and revitalizing the architectural style of the destinations. However, the implications and tourism interventions will be different from one destination to another in order to reflect local context and identity such as architecture style, cultural heritage and local lifestyle (Kaya,2014). Similarly, it is also possible for the regions with tourism paradox to disengage from this paradox, yet it is not quite easy as it is expected. Tourism destinations can be disengaged from this paradox to reach to the natural, historical, economic and ancient social positions through consistency in the society and with the help of scientific methods.

Mallorca Island in Spain is maybe the first resort that experienced the tourism paradox. They destroyed the natural environment as well as traditional architecture for the sake of tourism development. However to disengage from tourism paradox they tear down the huge hotels and reconstructed them with respect to nature on the island. Naturally the bed capacity in Mallorca declined. With the growth of the natural environment tourism income on the island has increased. This shows that tourism income has a tendency to increase, ifthe quality of the natural environment is improved.Tourism detox requires decreasing the demand of the number of beds in order to increase the income per bed and to disengage the region from dominant tourism activities.

\section{CONCLUSION}

Sustainable tourism should help define cultures, not reinvent them. Tourism frequently means the occupation of free space, the destruction of natural eco-systems, and the reestablishment of everyday life at the chosen destination. This activity is connected with the damage to the environment and to the local population. Many of the problems associated with tourism development arise from the fact that tourism providers are not sensitive to tourism equinox, local pressures and needs. To be successful, sustainable tourism has to rely on the local population and on its participation in development of tourism activity(Lopez\&Palomino,2003). 
Tourism itself is not an environmentally and socially "negative" activity that should be avoided. The tourism industry is worth developing and investing in and brings about negative impacts which sometimes outweigh its associated positive economic impacts if you do not care for tourism equinox. But the remarks about the negative impacts of tourism are intended to demonstrate and explain the tourism paradox.A sustainable tourism with tourism equinox is the only type of tourism that can offer an authentic countryside lifestyle area, where it is possible to relax and enjoy nature and countryside atmosphere, like in Tuscany, Provence andWachau,without compromising the other local specialization, first of all agriculture.Tourism equinox should be substantiated through policy and legislation and should be primary objective in all decisions regarding tourism. This covers a multitude of areas of study and implementation ranging from, but not limited to, environmental, social, economic and urban development and design.

- In the first place, the best way to start to reconstruction of tourism is to prepare a participative Tourism Development Plan.

- Tourism legislations should be "directive" rather than "compulsory".

- Common sense should prevail over policy, lessons learned from mistakes of other destinations should direct destination development.

- Most importantly tourism should not be conceptualized as a finite stream of revenue where profit maximization is the logical course of action, but as a renewable resource that requires care and attention in its utilization.

- Based on an understanding that is distinct from mass tourism, a new tourism destination where the cultural and historical heritage is utilized needs to be created through investment, promotion and marketing that is focused on sustainability.

- Activities necessary for strategic planning should be carried out, and the cooperation of public and private sectors should be ensured after determining the applicability of tourism equinox approach.

- Rural tourism must be promoted as a key driver of rural tourism development, and funds must be devoted to supporting the development of rural lodging establishments.

- The awareness of locals and visitors should be raised in order to prevent damage to the historical and cultural environment.

- Local population should be encouraged to participate in the new tourism strategy.

- The carrying capacity of the region should be determined under sustainable principles.

- Local authorities should be informed very clearly that it is not possible to achieve sustainable tourism development without respecting natural environment.

- Local governments, non-governmental organizations, universities and professional organizations should cooperate against adverse environmental effects caused by tourism.

- The success of this tourism approach depends on effective destination management and marketing involving the principles of tourism.

Holiday is no longer a luxury but has become a way of life. The freedom to travel is regarded as an unquestionable right nowadays. According to the theory discussed in this paper, the impact of tourism can be tragic for some tourist areas and even if more and more sustainable policies are being implemented, only the future will show if the damage caused 
by tourism can be erased by a new sustainable tourism (Lopez\&Palomino,2003) or with the help of tourism detox.

It is very hard to tear down the huge buildings like big hotels. The stakeholders of the tourism industry can be convinced by giving tax deductions and explaining the long term benefits of tourism detox. When succeeded, there will be a more balanced and controlled tourism development which is in harmony with natural and social environment. The best thing to do is to achieve "tourism equinox", then we don't have to worry about "tourism detox".

\section{REFERENCES}

Buswell, R. J., (2011).Mallorca and Tourism History, Economy and Environment. Bristol: Channel View Publications.

Diekmann, A. \&Gillot, L., (2010). Heritage and Tourism: A Dialogue of Deaf? The Case of Brussels. Led Online E-Journals, Rivista di Scienze del Tourismo Ambiente Cultura Diritto Economia (in English), Vol (3), pp.263-280.

Kaya, E., (2014).From Industrial and Residential to a Tourism Precinct: The Rocks of Sydney, University of Western Sydney,Australia.

Kılıç, S.E. \&Aydogan, M., (2015).Sustainable Tourismand Heritage in Sigacık/Seferihisar. International Journal of Social, Behavioral, Educational, Economic and Management Engineering, $\operatorname{Vol}(9), \operatorname{No}(1)$, p.310.

Lopez, L. \& Palomino, B., (2003).Impacts of Mass Tourism on Local Communities and the New Phenomenon of Colonization-Case Study: Majorca. MA Thesis, Bournemouth University, England, p.76.

Murayama, M. \& Parker, G., (2012). Fast Japan, Slow Japan: Shifting to Slow Tourism as a Rural Regeneration Tool in Japan. S. Fullagar, K.W. Markwell and E. Wilson (Ed.) Slow Tourism: Experiences and Mobilities, Bristol: Channel View Publications, pp.170-185.

Randelli, F., Romei, P., Tortora, M. \&Tinacci, M., (2012). Rural Tourism Driving Regional Development in Tuscany. The Renaissance of the Countryside, Department of Economic Sciences, University of Florence.

Segui, L., M., (1995). Les nouvellesBaléares. La Rénovation d'un Espace Touristique Mythique in L'Harmattan, ed. Paris, p.65.

Teo, P.\& Huang, S., (1995). Tourism and Heritage Conservation in Singapore. Annals of Tourism Research, 22(3), pp.58-615.

Timothy, D.J., \&, Boyd, S.W., (2003).Heritage Tourism, Pearson Education.

Wearing, S., Wearing, M. and McDonald M., (2012).Slow'n Down the Town to Let Nature Grow: Ecotourism, Social Justice and Sustainability. S. Fullagar, K.W. Markwell and E. 
Wilson (Ed.) Slow Tourism: Experiences and Mobilities. Bristol: Channel View Publications, pp.36-50.

http://www.gdrc.org/uem/eco-tour/envi/one.html. (18.01.2015)

http://www.karl.aegee.org/oem/articles/oe8/t-freedo.htm/p. (21.02.2015)

www.exofoundation.org/the-paradox- of-tourism.(29.12.2014) 